\title{
INTERNET USE AND THE POLITICAL KNOWLEDGE GAP IN SPAIN
}

\section{EL USO DE INTERNET Y LA BRECHA DE CONOCIMIENTO POLÍTICO EN ESPAÑA}

\author{
Eva ANduIzA eva.anduiza@uab.es \\ Universidad Autónoma de Barcelona. Spain
}

AinA GaLLEgo aina.gallego@upf.edu

Universidad Pompeu Fabra. Barcelona. Spain

LAIA JORBA laia.jorba@uab.es

Universidad Autónoma de Barcelona. Spain

\begin{abstract}
Media availability and fragmentation and the resulting possibilities of content selection have risen dramatically with the expansion of new digital media. Previous research has found that this may increase knowledge gaps among citizens with different resources and motivations. This article analyses how Internet use affects political knowledge gaps due to education and to political interest in Spain. As expected, frequent Internet users are more knowledgeable about politics than non-users. Furthermore, Internet use increases knowledge more for the highly educated than for citizens with lower levels of education. Thus, the political knowledge gap related to education seems to be growing with the introduction of new media. However, the knowledge gap between citizens with high and low levels of political interest is smaller for frequent Internet users than for non-users. These findings provide a complex picture and partially contradict the pessimistic theory about the impact of increasing media choice on political knowledge.
\end{abstract}

\section{KEYWORDS}

Internet; Knowledge Gap; Knowledge New Media; Political knowledge.

\section{RESUMEN}

La disponibilidad y fragmentación de medios de comunicación y las posibilidades de elegir contenidos han aumentado en gran medida a raíz de la expansión de los medios digitales. Estos pueden, según investigaciones anteriores, incrementar las diferencias en los niveles de conocimiento entre ciudadanos con distintas características. En este artículo se analiza cómo afecta el uso de Internet a las diferencias en el conocimiento político según el nivel educativo y el interés por la política en España. Los usuarios frecuentes de Internet saben más sobre política que los no usuarios, como era de esperar. Además, el uso de Internet incrementa el conocimiento político de manera más intensa para los usuarios con niveles educativos más elevados. Por tanto, parece que las diferencias en los niveles de conocimiento pueden estar creciendo con la expansión de los medios digitales. Sin embargo, las diferencias en el nivel de conocimiento de los más y menos interesados en política son menos pronunciadas entre los que usan Internet frecuentemente. Los resultados ofrecen una imagen compleja y matizan las teorías pesimistas sobre el impacto de la creciente posibilidad de elección de contenidos en los medios sobre el conocimiento político.

\section{Palabras clave}

Brecha de conocimiento; Conocimiento político; Internet; Nuevos medios de comunicación. 


\section{INTRODUCTION}

Political knowledge is linked to many attributes that define a good citizen: interest in politics; political involvement, discussion and participation; opinion consistency and stability; ability to evaluate governments and policies and to vote accordingly (Palfrey and Poole 1987; Zaller, 1992; Delli Carpini and Keeter, 1996; Lassen, 2005; Kim, Scheufele andShanahan, 2005; Fraile, 2007). However, political learning is costly and therefore not all people are equally knowledgeable about politics. Some citizens have higher levels of cognitive skills and it is relatively easy for them to make sense of what happens in the world and retain political facts. Other citizens have political motivations and extract an intrinsic satisfaction from devoting time and effort to be informed about politics: they are interested in politics, or feel that it is their obligation to keep an eye on the political world. Nonetheless, most citizens are under-informed about politics. According to Downs (1957) this is to be expected, as it is not rational to devote much time or effort to get detailed information about politics. We therefore find large variations in the extent to which citizens are knowledgeable about politics, depending on their levels of cognitive resources and political motivations. This phenomenon is referred to as the knowledge gap (Tichenor, Donohue and Olien, 1970).

Beyond individual resources and motivations, much political knowledge acquisition depends on the availability of free information provided by the context, and in particular by the media, which are the main sources of political information for citizens (Graber 2004). There is a lively debate on how media affect political attitudes and behaviours (see Newton 1999 for a summary). Recent research has emphasized the fact that these effects are contingent on the type of media: while some like the press tend to increase knowledge gaps, others like television may reduce them (Kwak, 1999; Jerit, Barabas and Bolsen, 2006). The question on the contingent effects of media exposure on political knowledge becomes all the more relevant as media environments have changed dramatically in the last years with the increasing availability of information and communication technologies. Changes in the media context are expected to produce changes in political knowledge.

The new media environment, and in particular the Internet, offers more choices for content selection than traditional media. People can now choose among a wider repertoire of information or entertainment content available in digital media. Political motivations are thus expected to play an important role when it comes to predicting exposure and attention to political information online, and thus also political knowledge. In addition, cognitive abilities such as level of education are expected to be more important in coping with the overwhelming flow of information available online, and in making sense

\footnotetext{
"The authors acknowledge the financial support provided under grant SEJ2007-60082 of the Spanish Ministry of Science and Innovation and by the Centro de Investigaciones Sociológicas. The data used for the analyses can be downloaded from www.cis.es.
} 
of political events in an increasingly complex world. While the most optimist accounts expected the Internet to increase the availability of political information and thus levels of knowledge, it seems that to the extent that these positive effects exist, they are mostly found in citizens with higher levels of resources and motivations (see for instance Kim, 2008; Prior, 2007).

This article analyses to what extent, as the theoretical arguments of previous research carried out based on US evidence would suggest, Internet use in Spain also produces an increase in knowledge gaps between citizens with different levels of education and political interest. The paper is structured in four sections. Section 1 explains the main theoretical arguments regarding the knowledge gap hypothesis. Section 2 briefly discusses the characteristics of the Spanish case and describes the data and variable operationalization. Section 3 presents the empirical analyses. Finally, the last section discusses the results.

\section{THE KNOWLEDGE GAP HYPOTHESIS AND THE EFFECT OF NEW MEDIA}

An increase in the availability of information in a given society does not affect every citizen equally. A classic research question on the heterogeneous distribution of political knowledge among population groups began with the knowledge gap hypothesis (Tichenor, Donohue and Olien 1970). According to this hypothesis, in rich information contexts, the gap in political knowledge between the most and least advantaged widens, leading to larger levels of political inequality. Contrary to the intuitive expectation that would lead us to believe that a greater amount of available information leads to increasing widespread political knowledge, the authors argued that as "the infusion of mass media information into a social system increases, segments of population with higher socioeconomic status tend to acquire this information at a faster rate than the lower status segments" (Tichenor, Donohue and Olien, 1970: 159-160). As the availability of information grows, the relative difference in political knowledge between the most and least advantaged groups enlarges due to their unequal learning speed. People in socially advantaged positions are better at acquiring and processing political information and they disproportionately benefit from an increased information supply (Bonfadelli 2000). This is so because they have better cognitive skills that reduce learning costs, and also higher motivations to pay attention to political information. A large amount of literature has tested this hypothesis (i.e. Genova and Greenberg, 1979; Jerit, Barabas and Bolsen, 2006; for a review see Gaziano 1997). Almost all studies have found evidence supporting the notion that as the information supply increases, the relationship between knowledge and socioeconomic status becomes stronger, regardless of the topics, methods and theoretical perspectives.

Thus, the acquisition of political knowledge is certainly affected by individuals' education and motivations, but we also need to take into account their media environment (Vettehen, Hagemann and Van Snippenburg, 2004). This media environment can widen or reduce the relative gap in knowledge levels among citizens with different resources or 
motivations (Bonfadelli 2000). As Tichenor, Donohue and Olien also argued, the impact of individual characteristics on knowledge is contingent on the type of media. Their theory applied mainly to the influence of newspaper reading on political knowledge, but did not work for television, which was seen as a "knowledge leveler". Newspapers cover a wide range of issue dimensions, not only providing facts, but also framing issues with explanations of causes and consequences. These give readers a more complete picture of the story and contribute to hard political knowledge and efficacy (Neuman, Just and Crigler, 1992). Television, on the other hand, is better suited to exploiting the visual impact of news, emphasizing their emotional and dramatic components (Graber, 2004), and presenting information in a less sophisticated manner that demands lower skills. Even if the audience lacks political motivations and cognitive skills, they can still learn significantly (Eveland and Scheufele, 2000; Kim, 2008; Graber, 1990). Thus, while newspapers tend to increase knowledge gaps between the advantaged and the disadvantaged, television works as a knowledge leveller in the sense that "least educated benefit nearly as much as the most educated (and in terms of relative gains, they do better)" (Jerit, Barabas and Bolsen, 2006: 278).

We are now in a transition towards a high choice media environment characterized by the expansion of new information and communication technologies and the explosion of available information at least for those with Internet access. These recent changes are deeply affecting the population's habits and they should also have an impact on political knowledge. The new media environment can be characterized as a high choice setting (Prior, 2007). A few decades ago TV, radio and newspapers were the key sources of information and interpretation of the political world. This was a low choice environment in the sense that the supply of information and entertainment was limited. Taking TV, for instance, not only were there far fewer channels, but also less diversity in terms of content. It was not possible for citizens to choose from among different options depending on their motivations and preferences. Today, with the expansion of Internet and cable $\mathrm{TV}$, there are many more alternative sources of information. Citizens can monitor their exposure to news and other media content much more efficiently: they can continue with a political debate after the news, or they can skip the news altogether. The media context scenario has changed dramatically on the supply side of information and entertainment. More than any other new media, the Internet is the flagship of this revolution. The question thus arises: how does Internet use affect political knowledge acquisition and political knowledge gaps?

The effects of Internet use on political knowledge are important because they have implications for the digital divide. As Van Dijk (2006: 232) argues, one of the limitations of the literature on the digital divide is the lack of empirical analysis of its consequences. A significant relationship between Internet use and political knowledge provides empirical support for the idea that access to computers and the Internet is a source of relevant political information which in turn may mean power (Castells 1996). Additionally, an enlargement of the knowledge gap due to Internet use implies that digital inequalities add to traditional sources of inequality (van Dijk, 2006: 231). 
The discussion of how Internet use affects political knowledge mirrors the more general debates of media effects. While some argue that the expectation is that Internet use increases knowledge (mainly by reducing information costs, see Bimber, 1998, 2001), others argue that it could even reduce it by allowing people to devote more time to entertainment than to getting political information (see Sunstein 2003).

As these changes are very recent, the empirical evidence is still scarce and mostly focuses on the US case, but most works find a positive effect of Internet use on political knowledge (Althaus and Tewksbury, 2002; Eveland, Cortese, Park, and Dunwoody, 2004; Kenski and Stroud, 2006; Dalrymple and Scheufele, 2007; Beaudoin, 2008; Kim, 2009). Others find no significant effects (Johnson, Braima and Sothirajah, 1999; Scheufele and Nisbet, 2002; Eveland and Dylko, 2007'1). With the exception of Sunstein's (2006) work, which includes some qualitative data on knowledge errors and bad decisions in online contexts, to our knowledge there is no empirical research showing a significant direct negative relation between Internet use and political knowledge.

The positive effect is, however, relatively small (see Kenski and Stroud, 2006; Grönlund 2007; but see Beaudoin 2008), effective for issue knowledge (Althaus and Tewksbury, 2002; Kim, 2009), and viewed as a complement rather than substitute for other mass media like TV or newspapers (Dalrymple and Scheufele, 2007). Althaus and Tewksbury (2002) confirm that online news media facilitate greater individual control over news exposure and issue knowledge; they are optimistic about the results as long as general information is provided by other means. Dalrymple and Scheufele (2005) also support this last point when stating that new media should be used with traditional media in order to obtain more effective results in both integrated and differentiated knowledge. Eveland et al. (2004) show how digital interfaces might increase what they call "knowledge structure density" more than factual learning, which is better facilitated by other mass media.

Arguably, it is important to consider not only the structural media context (i.e. the availability of information, Kim, 2008; Curran et al., 2009), but also the use of specific media and the degree of exposure to political information (Kwak, 1999; Shah, Kwak and Holbert, 2001; Kenski and Stroud, 2006; Van Dijk, 2006). For instance, Scheufele and Nisbet (2002) report a negative effect of the entertainment uses of the Internet on political knowledge, but no significant relationship when testing for the effect of online political uses.

Even if most previous research points to a positive (if limited) effect, this may still be concentrated among those with greater resources and higher motivational levels, therefore increasing knowledge gaps and levels of political inequality. In fact, we have good reason to expect that the extent to which Internet use facilitates the acquisition of political knowledge is dependent on previous levels of cognitive skills and political motivations. Cognitive abilities are important to understand a complex, plural world with

\footnotetext{
${ }^{1}$ The authors argued in this case that the null effect of blog use on knowledge before and after the 2004 presidential election was probably due to the early stage of blog diffusion at that time. The same could be applied to Johnson et al., who refer to the 1996 election when levels of Internet diffusion were still low.
} 
a large amount of available information which certainly characterizes the new media scenario. More information does not necessarily mean better quality information. The large availability of online information does not come with the necessary abilities to process and assimilate it (Polat, 2005; Bimber, 2003; Clément, 2002; Noveck, 2000). Cognitive abilities are necessary in order to sort out the important from the superfluous, the hard facts from the improbable, particularly in a context where anyone could feel overwhelmed by the amount of information available. Online information format is closer to text-based newspapers than to visual television (Norris and Sanders, 2003): it is harder to process, and this would lead to reinforcing inequality patterns in knowledge acquisition. Therefore, education is expected to strongly condition how Internet use affects political knowledge as cognitive abilities are necessary to manage a complex, diverse and huge amount of information. It can be expected that the political knowledge gap between citizens with different levels of education widens for people who use the Internet frequently because highly educated citizens are better able to understand and process the information that they read online, whereas people with lower levels of education would be less able to do so.

This is a reformulation of the classical knowledge gap hypothesis (Tichenor, Donohue and Olien, 1970), which as already argued, refers to the faster and more effective way in which educated people acquire knowledge from mass media. Previous research has pointed at the crucial interactive effects between Internet use on the one hand, and education and motivation on the other (Bonfadelli, 2000). In online contexts, skills are of more importance than education per se (Eveland, Marton and Seo, 2004, Anduiza, Gallego and Cantijoch, 2010). Besides, motivation may also intervene, modifying the distribution of political knowledge (Prior, 2005, 2007).

From our point of view, Prior (2007) has formulated the most thoroughly articulated claim on the growing role of motivation in high choice media environments. The core of his argument is that most people have a basic preference either for entertainment or for news content, but that the actual consumption of political information and subsequent political learning depends on the options provided by the media environment. In a low choice environment, little content can be selected, there are more inefficiencies in the media systems and many people end up learning about politics even if they are not purposely looking for political content. This observation is exemplified by the fact of watching evening news on TV. When all channels broadcasted news in the evening, most people kept in touch with politics, even if they were uninterested, if only because at that time of the day there was nothing else on the screen. The new media environment, on the contrary, is characterized by the enormous possibilities of content selection. People in a high choice media environment are able to select among an almost unlimited set of options. Once given the choice, exposure to the news will depend on motivation: people who want to learn about politics will follow the available political information online, but those who are not interested will easily skip political content and choose entertainment options instead.

Prior's theory is mainly developed to account for the impact of the transition from broadcasted television to the cable television system. However, the argument is gene- 
rally based on the idea that having more choices affects the actual selection of content. This argument applies to the Internet because it dramatically increases the possibilities of choosing the content that individuals prefer (Norris, 2001; Eveland and Scheufele, 2000). The prediction of this theory is that the consumption of political information on the Internet is more strongly mediated by motivation than it is in traditional media such as broadcast television. What follows is that the more media people consume on the Internet, the more the knowledge gaps between those who are interested in politics and those who are not should grow. Thus, motivation would be a main driving force for following political information and thus increasing political knowledge among those that use the Internet.

To sum up our hypotheses, we expect to find both direct effects and interaction effects. First, we expect to find direct positive effects of Internet use on political knowledge (h1). According to the literature, education (h2) and political interest (h3) are also expected to increase political knowledge. Second, we expect to find interaction effects between education and Internet use (h4) and between political interest and Internet use (h5), because we expect larger effects of these variables among frequent Internet users.

\section{The Spanish CONTEXT, dATA AND OPERATIONALIZATION}

As is usually the case, most theories on the impact of the media have been developed and tested in the US. However, it is important to test the theories in other contexts for two main reasons. First, if the results are similar in different settings, the validity of the theoretical arguments and the robustness of the empirical findings would be reinforced. Second, analysing what happens in different countries is necessary to understand how contexts condition the logic of individual attitudes and behaviour. Indeed, a growing strain of research points out that differences in the regulation and characteristics of media systems lead to different content being broadcasted and this affects political knowledge (Curran et al., 2009). In Spain, the traditional media ${ }^{2}$ system and the framework for programming and advertising is regulated by the state and controlled by independent agencies. Even when channels are both in public and private hands, $80 \%$ of the audience is

\footnotetext{
${ }^{2}$ We classify television, radio and newspapers as traditional communication media, which have a longer history in our societies and do not facilitate content selection. Digital television and the Internet are considered new media or digital media. The main criterion to distinguish between traditional and new media is not chronological, which by definition would dilute as time goes by, but typological. New media or digital media allow interactivity and increase the possibilities of content selection dramatically. Although traditional media are ruled by different policies, their content has a similar structure. All of the media have similar news sections: international, national, society, culture, sports, and so on. This means that traditional media consumers, regardless of the channel or newspaper chosen, are exposed to information that does not necessarily interest them, because it is similar to other content. Editorial decisions play a very important role in this context and the agenda is largely dominated by just a few actors. News is provided by the same agencies and the full provision of news across different media is quite similar, even if the ideological interpretation differs.
} 
concentrated in two public channels and two private ones. ${ }^{3}$ In Spain, almost all broadcast channels offer news at $3 \mathrm{pm}$ and at $9 \mathrm{pm}$. At those moments of the day, people who do not have pay-TV (which has a marginal role in Spain) or do not use Internet at home have only two options: watch the news or turn off the TV. At the time we collected our data (autumn 2007), a large segment of the Spanish population belonged to a low choice media environment: $48 \%$ of the Spanish population had neither cable TV nor the Internet at home. This fact allows us to test the differences between people in a high choice and a low choice media environment by analysing the effect of Internet use as an indicator of a high choice environment. The expectation is that in a traditional media system (without Internet use) there is higher exposure to political news for everyone, and thus political knowledge gaps should be lower.

On the contrary, new media are not yet fully regulated and have just begun to be widely used in recent years. Digital television was not a usual asset in Spanish homes at the moment of the survey. In late 2007 , only $26 \%$ of the respondents to our survey reported that they had pay-TV at home and this variable does not affect political knowledge or the knowledge gap in a significant way. ${ }^{4}$ By contrast, about $50 \%$ of the population reported that they were Internet users when the survey was carried out. This figure is similar to that reported by other surveys conducted in the same year. A $50 \%$ split between users and non-users is very adequate to study the impact of the availability of the Internet in the Spanish case in a cross-sectional study. In the absence of longitudinal data, which would be better when it comes to studying the impact of the spread of new media on political knowledge, a second-best research design consists in comparing political knowledge according to frequency of Internet use.

For the analysis, a personal survey was administered to 3,739 respondents who were representative of the Spanish population. The survey was conducted in November $2007 .{ }^{5}$ The sample included an overrepresentation of people aged 18 to 40 years in order to have a high number of Internet users and the survey is therefore particularly suitable for testing theories on the impact of new media. ${ }^{6}$

The dependent variable of interest is political knowledge, which was measured by adding the correct answers to three factual knowledge questions which were asked in the survey. Specifically, the respondents were asked to name the president of their regio-

\footnotetext{
${ }^{3}$ Digital television, which became widespread in 2010, has recently started to change this. But this has no implications for this research because the data were gathered at an earlier date.

${ }^{4}$ The data are not shown in this article but available from the authors upon request.

${ }^{5}$ The questionnaire was designed specifically to analyse the relationship between Internet use and political engagement. The fieldwork was carried out by the Centro de Investigaciones Sociológicas (CIS) and the data can be downloaded from its website (www.cis.es study number 2637). An English version of the questionnaire is available from the authors upon request.

${ }^{6}$ Thus, data need to be weighted to correct for the overrepresentation of younger individuals, and also for other elements of the sample design. Adequate weighting variables are provided with the data and applied in all analyses in this article.
} 
nal government, the minister of employment and social affairs, and the president of France. The possible values of the scale were reporting no correct answer, one, two, or three correct answers (see the Appendix for the coding details of all the variables). It has been convincingly argued that information is not knowledge (Grönlund, 2007): the first can be simply an accumulation of data, while the latter is understood as the accurate use of information to make sense of the political world. ${ }^{7}$ But even if both concepts are not the same from a theoretical point of view, knowledge is frequently measured as a correct answer to some political issues and factual questions, which would strictly account for political information. There are more complex operationalizations of political knowledge that distinguish between knowledge about the political system, everyday politics and ideological differences among actors. ${ }^{8}$ However, Delli Carpini and Keeter (1996) conclude that there is a basic common dimension of political knowledge. Moreover, as Jerit, Barabas and Bolsen (2006) explain, general knowledge is more stable and highly dependent on socialization, while specific-domain knowledge questions are preferable to measure variability and updating of knowledge, and consequently the impact of the information environment.

In our analysis we consider Internet users as people who are exposed to the new media and thus belong to a high choice environment, while non-users are considered to be in a low choice environment. We distinguish between overall exposure and specific political uses of the Internet. Internet use, or overall exposure, is measured as an ordinal variable based on a question that asks how frequently the respondent uses the Internet, ranging from never, to 6/7 days a week. In addition, we include a variable that accounts for the frequency with which the respondent uses the Internet to keep informed about politics.

The consumption of traditional media is likewise split between overall use and political uses. We include a variable that asks how many hours a respondent spends every day watching television or listening to the radio. This variable accounts for overall exposure to these media. As for political uses, we include the frequency with which respondents read newspapers (excluding the sports press), and the frequency with which respondents report that they watch or listen to the news on TV or the radio.

We do not have direct measures of cognitive abilities, but we use education as a proxy variable for them. Education is coded by means of 5 categories, which range from having no schooling to having tertiary education. The key motivation variable that we take into account is political interest. Interest is one of the most important predictors of

\footnotetext{
${ }^{7}$ Political sophistication (Luskin, 1987) is another related concept which is also measured using political knowledge indicators.

${ }^{8}$ Traditionally, only two categories have been used: general or civic knowledge versus policy or specific facts and issues- knowledge (Kim, 2008). For instance, Genova and Greenberg (1979) refer only to structural political knowledge, what we call political system knowledge; and factual knowledge, which includes the other two categories of political knowledge described above. Prior (2005) also uses a similar double category in which he distinguishes between civic knowledge and political knowledge.
} 
political attentiveness and engagement. Although it is still unclear where political interest comes from, we know that it is one of the pathways that link socio-economic status to political behaviour and that it also has an independent effect on it (Verba, Schlozman, and Brady, 1995). Political interest is divided into four categories, going from not at all to very interested.

Finally, we have included a number of variables which can be expected to affect the levels of political knowledge such as socio-demographic characteristics, and the frequency of political discussion. As there are many missing values in the income variable, we have imputed those by regressing income on 20 variables and imputing the predicted income to each missing value. A variable age squared has been introduced to account for the likelihood that the relationship between age and knowledge is not linear. All variables except for age and age squared are recoded to range from 0 to 1 .

\section{AnALYsIS}

We begin our analysis by examining the magnitude of the knowledge gap across different individuals. The following figures report the mean number of correct items reported by respondents with different levels of education (figure 1) and interest in politics (figure 2). As there were three knowledge items, the maximum number of correct items is three, while the minimum is zero. It is clear that there is a strong, positive and linear relationship between education and political knowledge and between political interest and political knowledge. ${ }^{9}$ On average, those who are highly educated or very interested in politics are able to give more than twice as many correct answers to the political knowledge questions than those who have not completed primary education or those who are completely uninterested in politics.

Next, we want to examine the determinants of political knowledge in order to understand which factors are relevant when it comes to increasing such knowledge or not. According to the arguments put forth in the first section of this article, political knowledge should depend on the media environment in which a person lives because it shapes the opportunities and the alternatives for political learning (h1), on cognitive resources such as education (h2), and on motivations such as political interest (h3). We also need to control for other relevant factors that can be expected to influence political knowledge such as the frequency of political discussion, socio-demographic characteristics and exposure to traditional media. In addition to overall media exposure, we also examine the specific impact of political media exposure. As all the variables except for age are coded to range between 0 and 1 , we can roughly compare the magnitude of the coefficients, which are

\footnotetext{
${ }^{9}$ One-way analyses of variance by levels of education and interest in politics confirm that the mean level of political knowledge differs significantly across categories of the independent variables.
} 
interpreted as the change produced in the scale of political knowledge when we move from the maximum to the minimum value of each independent variable.

The hypothesis regarding the direct effects of frequency of Internet use, education and interest in politics are all confirmed by the data. As expected, political interest, education and age are the most powerful predictors of political knowledge. All other variables

Figure 1.

The knowledge gap in Spain by education

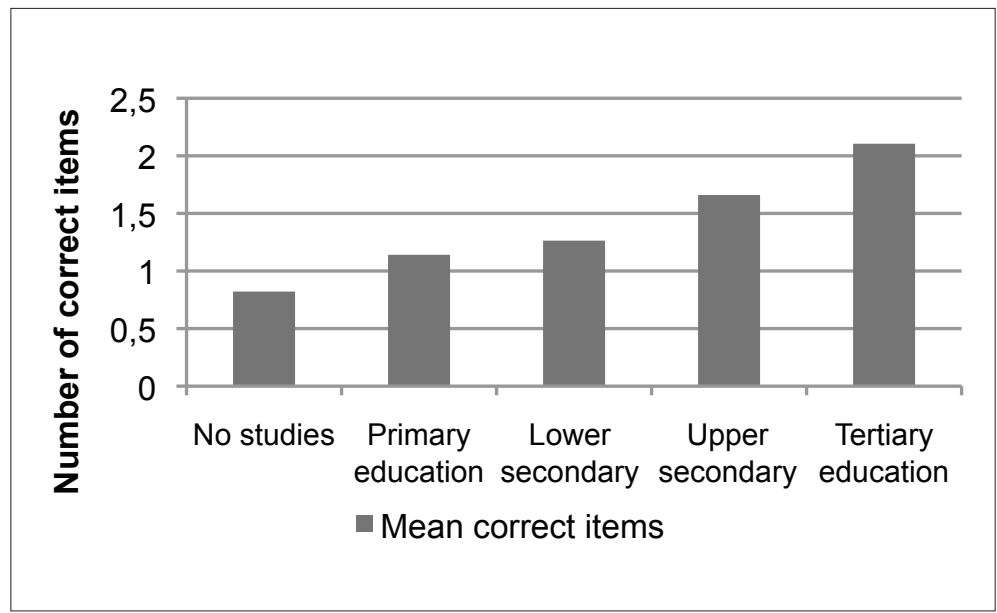

Source: Own elaboration based on CIS study number 2637.

Figure 2.

The knowledge gap in Spain by political interest

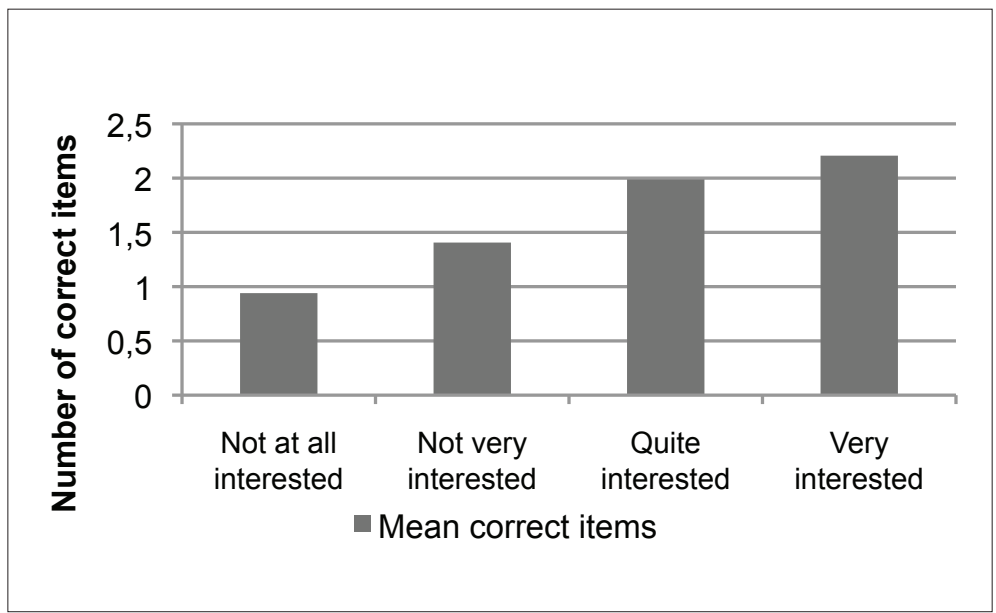

Source: Own elaboration based on CIS study number 2637. 
Table 1.

Determinants of political knowledge in Spain

\begin{tabular}{lll}
\hline & Coef. & SE \\
\hline Hypothesized direct effects & & \\
\hline H1: Internet use & $0.044^{* * *}$ & 0.016 \\
H2: Education & $0.241^{* * *}$ & 0.022 \\
H3: Political interest & $0.179^{* * *}$ & 0.022 \\
\hline Controls & & \\
\hline Income & $0.112^{* * *}$ & 0.034 \\
Age & $0.018^{* * *}$ & 0.002 \\
Age squared & $0.000^{* * *}$ & 0.000 \\
Woman & $-0.104^{* * *}$ & 0.009 \\
Political discussion & $0.126^{* * *}$ & 0.019 \\
Entertainment TV and radio & $0.040^{* *}$ & 0.018 \\
News in TV and radio & 0.025 & 0.021 \\
Newspaper reading & $0.090^{* * *}$ & 0.013 \\
Political information online & $0.041^{* *}$ & 0.018 \\
Constant & $-0.351^{* * *}$ & 0.041 \\
$\mathrm{~N}$ & 3.597 & \\
Adjusted R2 & 0.364 & \\
\hline
\end{tabular}

Coefficients are not standardized ${ }^{* * *} p<0.005 ;{ }^{* *} p<0.05 ;{ }^{*} p<0.1$

Source: Own elaboration based on CIS study number 2637.

included in the analysis have the expected effect with the exception of exposure to news on television or radio. People who report seeing or listening to the news on television or on the radio are often not any more knowledgeable about politics than people who do not regularly watch the news. One explanation could be that watching the news on television or listening to it on the radio is correlated with other variables in the model that take the explanatory burden, leaving exposure to television and radio news without effect. Although there are some expected high correlations among the explanatory variables included in the model ${ }^{10}$, the correlation coefficient of exposure to news with the other

\footnotetext{
${ }^{10}$ The strongest correlations, besides the correlation between age and age squared, are those between political interest and political discussion (0.72), frequency of Internet use and education $(0.60)$ and education and income (0.56).
} 
variables is never higher than 0.21 and thus we can rule out the problem of multicolinearity. A second explanation for this unexpected effect may be that people do not learn any factual knowledge from their news consumption on television, which is implausible given previous literature that regards news viewing as a knowledge leveller. A third possibility is that self-reported news consumption as measured here (which is the way it is measured in many other international surveys) is a poor measure of actual exposure and attention to news. It might be that many people over-report viewing news because they think that it is socially desirable. This argument has been put forward by Prior (2009) and, although we cannot test it empirically, it could be the reason for this unexpected null effect.

We now move to the main objective of this article, which is to anlayse the impact of media environments on knowledge gaps. We want to know if using the Internet disproportionately fosters the political knowledge of people with more education, or with more interest in politics. This differential impact on some kinds of people would lead to widening knowledge gaps. We test this possibility by introducing interaction terms between education, political interest and frequency of Internet use in the regressions. The interaction terms test the hypothesis that some segments of the population (the well-educated or the poorly educated; the interested or the uninterested in politics) disproportionately benefit from their frequent exposure to the Internet. That is to say, we examine if some people increase their level of political knowledge more than others when they use this new medium. ${ }^{11}$

The first model in table 2 shows that the knowledge gap between the highly educated and the poorly educated is larger for Internet users than for non-Internet users. The coefficient associated to the main effect of Internet use is not significant, which means that for those with low levels of education, using the Internet now has no significant positive effect on political knowledge. However, the interaction between education and Internet use is positive and significant. This means that for high levels of education, using the Internet frequently does increase levels of political knowledge. This fact suggests that Internet use reinforces knowledge gaps because the highly educated who use the Internet know more about politics than their less educated fellow citizens who spend time online. This is the kind of reinforcing effect that was expected because cognitive abilities are hypothesized to be important for political learning in a textual, information-rich and complex medium such as the Internet.

The second model of table 2, however, obtains an entirely different result. The main effect of using the Internet is still positive and significant, thus frequent Internet users with no interest in politics know more about politics than non-Internet users, even after controlling for other factors. However, the interaction between political interest and Internet

\footnotetext{
${ }^{11}$ Two different regressions were run because interaction terms need to be interpreted taking into account the main and the interaction effects and interpretation becomes difficult when various interaction terms are included simultaneously. However, the sign and level of significance are the same with different model specifications.
} 
Table 2.

Internet use and the knowledge gap in Spain.

\begin{tabular}{|c|c|c|c|c|}
\hline & \multicolumn{2}{|c|}{ Interaction with education } & \multicolumn{2}{|c|}{ Interaction with political interest } \\
\hline & Coef. & SE & Coef. & SE \\
\hline \multicolumn{5}{|c|}{ Hypothesized interaction effects } \\
\hline H4: Education*Internet use & $0.106^{* \star}$ & 0.044 & & \\
\hline H5: Interest*Internet use & & & $-0.091^{* *}$ & 0.037 \\
\hline \multicolumn{5}{|l|}{ Main effects } \\
\hline Internet use & -0.021 & 0.032 & $0.074^{* \star *}$ & 0.020 \\
\hline Education & $0.196^{\star \star *}$ & 0.029 & $0.241^{* \star *}$ & 0.022 \\
\hline Political interest & $0.179^{\star \star \star}$ & 0.022 & $0.220^{\star \star \star}$ & 0.028 \\
\hline \multicolumn{5}{|l|}{ Controls } \\
\hline Income & $0.114^{\star * *}$ & 0.034 & $0.111^{* * *}$ & 0.034 \\
\hline Age & $0.018^{\star \star \star}$ & 0.002 & $0.018^{\star \star \star}$ & 0.002 \\
\hline Age squared & $0.000^{* \star \star}$ & 0.000 & $0.000^{\star \star *}$ & 0.000 \\
\hline Woman & $-0.106^{\star * *}$ & 0.009 & $-0.103^{\star * *}$ & 0.009 \\
\hline Political discussion & $0.127^{\star \star *}$ & 0.019 & $0.123^{\star \star \star}$ & 0.019 \\
\hline Entertainment TV and radio & $0.041^{* \star}$ & 0.018 & $0.040^{\star *}$ & 0.018 \\
\hline News on TV and radio & 0.027 & 0.021 & 0.023 & 0.021 \\
\hline Press consumption & $0.091^{* * *}$ & 0.013 & $0.090^{* * *}$ & 0.013 \\
\hline Political info. online & $0.034^{*}$ & 0.019 & $0.057^{\star * *}$ & 0.019 \\
\hline Constant & $-0.331^{* * *}$ & 0.042 & $-0.364^{* * *}$ & 0.041 \\
\hline$N$ & 3597 & & 3597 & \\
\hline Adjusted R2 & 0.367 & & 0.368 & \\
\hline
\end{tabular}

Coefficients are not standardized ${ }^{* * *} p<0,005 ;{ }^{* *} p<0,05 ;{ }^{*} p<0,1$.

Source: Own elaboration based on CIS study number 2637.

use is negative and significant. The interpretation of this unexpected result is that political interest is less important for political knowledge among frequent Internet users than for non-Internet users. The knowledge gap between those who are interested in politics and those who are not closes when people go online. This finding is more surprising from a theoretical point of view because most previous research suggests that motivation should be a stronger predictor of political learning in high choice media settings. 
Since it is difficult to interpret the magnitude of the effects reflected by the interaction terms, figures 3 and 4 graphically display the predicted level of political knowledge (in a scale ranging from 0 to 1) of people who are not Internet users and for frequent Internet users (six to seven days a week) by levels of education (figure 3 ) and political interest (figure 4). We need to specify the values of the other variables in the model in order to calculate the predicted political knowledge for different kinds of individuals. The values displayed correspond to 40-year-old women and the level of all the other relevant variables has been set to their respective means. ${ }^{12}$ The graph makes clear that the political knowledge gap between those interested and those uninterested in politics is smaller in the case of frequent Internet users than for non-Internet users. In other words, there are more similarities between politically interested and uninterested heavy Internet users regarding their level of political knowledge than with non-users, even after controlling for a wide set of variables. Motivation seems to play a smaller role for political learning in the Internet high choice environment than in the traditional low choice environment of those who do not use the Internet.

Figure 3.

Knowledge gap by education interest and Internet use

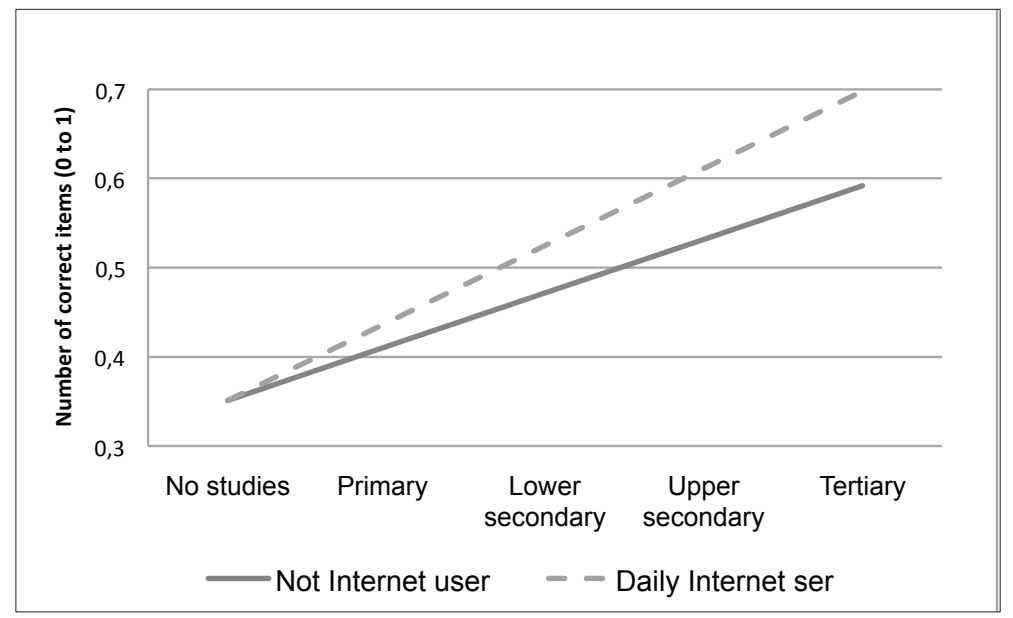

Source: Own elaboration based on CIS study number 2637.

\footnotetext{
${ }^{12}$ The only exception is that for non-Internet users the value of consuming political information online has been set to zero for logical coherence (non Internet users cannot possibly read news online), while it has been set to the mean for Internet users.
} 
Figure 4.

Knowledge gap by political interest and Internet use

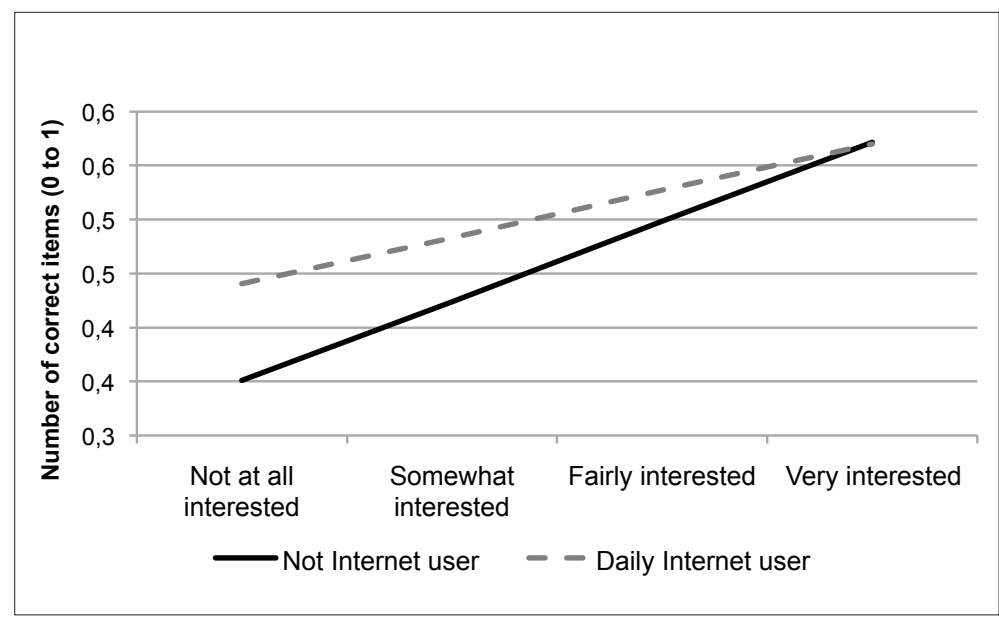

Source: Own elaboration based on CIS study number 2637.

\section{Discussion}

In this article we have examined a variant of the knowledge gap hypothesis focusing on the impact of Internet use on political knowledge for the Spanish case. The knowledge gap hypothesis clearly leads us to think that the spread of the Internet should widen the knowledge gap related to cognitive abilities because such abilities are increasingly important in a complex world of informational exuberance (Chadwick 2011). We have tested and proved that in Spain, following what has previously been found in other countries, the use of new information and communication technology exacerbates the relationship between education and political knowledge, thereby increasing knowledge gaps due to education. Knowledge gaps between those with more and less cognitive resources widen in the high media choice environment of the Internet. In other words, the most highly educated citizens take greater advantage of the new opportunities offered by the Internet, which require advanced cognitive abilities and capacities to process an overwhelming quantity of information available online.

While following news on the radio or television is a knowledge leveler ${ }^{13}$, the Internet

${ }^{13}$ The analyses (not reported here but available upon request) find a significant interaction between television and radio news exposure and education in the expected direction of reducing knowledge gaps. However, there is no significant interaction effect between newspaper reading and education, contradicting previous findings for the US. 
seems to be, conversely, a gap magnifier for people with different cognitive abilities. Citizens with lower levels of education increase their levels of political knowledge disproportionately more than the highly educated if they are exposed to television and radio news. But the knowledge level of those with more education that go online increases faster than the knowledge of the poorly educated who also go online. However, this confirmatory finding needs to be qualified. Motivation was also expected to increase knowledge gaps. In a high choice environment, people would only choose to be exposed to political content online if they prefer political content over entertainment. Because political interest can be considered an indicator of preference for political content, we expected an interaction between interest in politics and Internet use. However, our data show that this interaction takes the opposite direction: the knowledge gap is smaller among those with low levels of interest in politics. This is so because people with low levels of interest in politics that go online frequently have higher levels of political knowledge than those with low interest that do not go online. It seems that there is no need to be entirely pessimistic about the consequences of Internet diffusion and its impact on increasing political inequalities as there seem to be positive effects on the knowledge levels of the uninterested.

Although the argument that Internet would reinforce knowledge gaps due to motivation and preferences seems to be relatively dominant in the literature, some authors have pointed to several reasons why Internet use may have a positive effect on the political knowledge of the politically uninterested, or be a knowledge leveler at least in some cases. In the Internet, unlimited information can be obtained with relatively little effort (Bimber 2001). While it is true that those who actively search for information are interested, the high degree of interactivity and horizontality in Internet use may provide opportunities for learning about politics even for people who do not actively search for such information. We can identify three main mechanisms why this could happen.

Firstly, many web pages contain news portals including the well-known email servers. Many users, even if they are not interested in politics, read news headlines while making use of the Internet for other purposes such as consulting their email boxes. Similarly, many web pages or blogs on non-political issues or social networks contain some pieces of political information intermixed with other kinds of content. In other words, there are many non-political sites which contain at least some political news and information. People who are not interested in politics are likely to encounter and read some political information while being online. Thus, in spite of being a high choice environment, one could argue that the Internet is still quite inefficient.

Secondly, many Internet users spend hours online. According to our survey, 67 per cent of Spanish Internet users admit that they usually surf the net with no particular purpose or aim. These Internet users just spend time online looking at web pages in an unplanned way. Surely, being online is a form of entertainment, and although entertainment may be the type of content that people are mostly interested in, exposure to some unintended political information is likely to occur if people spend long hours online. Thus we can expect that some people who are uninterested in politics, but spend time surfing 
the net may randomly learn some facts about politics as they entertain themselves going from one web page to another.

Finally, the Web has another characteristic that may contribute to explaining why the uninterested may still increase their knowledge levels when they go online. The Internet, and this makes it fundamentally different from digital TV, provides a large number of possibilities for content production (Flanagin and Metzger, 2001) and this fact might be consequential for the present research question. Prior's thesis has been developed mainly to account for a situation in which citizens choose from among different television channels, according to their preferences, and act as market consumers. However, in the Internet, and particularly in the Web 2.0, users may not only choose to visit or not certain web pages according to their preferences, but be deeply embedded in networks of friends and acquaintances that continuously produce content and send information. Email is a good example of this. Many users receive unsolicited emails with political content sent by friends, family or workmates (Gibson, Lusoli, and Ward 2005: 577). Regardless of the recipients' political interests, it is very likely that they will read the political email they receive, just because they have been sent by someone they know. This also occurs in blogs and social networks. Users are therefore not isolated consumers in a market, but are embedded in complex networks and make decisions taking different criteria into account. Unlike the case of cable television, people online do not only take into account their preferences when consuming content. The Internet can be seen as a context in which the ability to decide about which contents to consume is much more determined by factors other than motivation as in the case of cable television.

These arguments may explain why Internet use does not necessarily need to widen knowledge gaps due to motivation. They hint at different mechanisms by which some people who are not interested in politics can increase their knowledge levels about politics while being online. While cognitive resources seem to be necessary to make sense of complex, rich, fragmented online information -and thus the knowledge gap due to education increases for Internet users - motivation is not. Further research should analyse these potential explanatory mechanisms, focusing with more detail on the specific uses of the Internet.

\section{RefERENCES}

Althaus, S., and D. Tewksbury. 2002. "Agenda Setting and the 'New' News. Patterns of Issue Importance Among Readers of the Paper and Online Versions of the New York Times". Communication Research 29 (2): 180-207.

Anduiza, E., Gallego, A. and M. Cantijoch. 2010. "Online Political Participation in Spain: The Impact of Traditional and Internet Resources". Journal of Information Technology and Politics 7: 4.

Beaudoin, C. E. 2008. "The internet's impact on international knowledge." New Media \& Society 10 (3): 455-474. 
Bimber, B. 1998. "The Internet and Political Transformation: Populism, Community, and Accelerated Pluralism." Polity 31 (1): 133-160.

Bimber, B. 2001. "Information and Political Engagement in America: The Search for Effects of Information Technology at the Individual Level." Political Research Quarterly 54 (1): 53-67.

Bimber, B. 2003. Information and American Democracy. New York: Cambridge University Press.

Bonfadelli, H. 2000. "The Internet and Knowledge Gaps. A Theoretical and Empirical Investigation." European Journal of Communication 17 (1): 65-84.

Castells, M. 1996. The Information Age. Economy, Society and Culture. Oxford; Malden, MA: Blackwell.

Chadwick, A. 2009. "Web 2.0: New Challenges for the Study of E-Democracy in an Era of Informational Exuberance". I/S: A Journal of Law and Policy for the Information Society 5 (1): 9-41.

Clément, M. 2002. "Internet, l'avenir radieux!." Pp. 267-273 in L'Internet en politique: des Etats-Unis à l'Europe, edited by V. Serfaty. Strasbourg: Presses Universitaires de Strasbourg.

Curran, J., lyengar, S., Brink Lund, A., and I. Salovaara-Moring. 2009. "Media System, Public Knowledge and Democracy: A Comparative Study." European Journal of Communication 24 (1): 5-26.

Dalrymple, K. E., and D. A. Scheufele. 2007. "Finally informing the electorate? How the Internet got people thinking about presidential politics in 2004." Harvard International Journal of Press/Politics 12 (3): 96-111.

Delli Carpini, M. X. and S. Keeter. 1996. What Americans Know about Politics and Why it Matters. New Haven: Yale University Press.

Dimaggio, P., and E. Hargittai. 2001. "From the Digital Divide to Digital Inequality: Studying Internet Use as Penetration Increases." Working Paper 15. Centre for Arts and Cultural Policy Studies, Princeton University.

Downs, A. 1957. An Economic Theory of Democracy. New York: Harper \& Row.

Eveland, W. P., Cortese, J., Park, H. and S. Dunwoody. 2005. "How Web site organization influences free recall, factual knowledge, and knowledge structure density." Human Communication Research 30 (2): 208-233.

Eveland, W. P, Marton, K., and M. SEO. 2004. "Moving beyond 'just the facts': The influence of online news on the content and structure of public affairs knowledge." Communication Research 31(1): $82-108$.

Eveland, W. P. and I. Dylko. 2007. "Reading Political Blogs During the 2004 Election Campaign: Correlates and Political Consequences." Pp. 105-126 in Citizenship, and the Future of Media, edited by M. Tremayne. New York: Routledge.

Eveland, W. P. and D. A. Scheufele. 2000. "Connection News Media Use with Gaps in Knowledge and Participation." Political Communication 17 (3): 215-237.

Flanazin, A. J., and M. J. Metzger. 2001. "Internet use in the contemporary media environment." Human Communication Research 27 (1): 153-181. 
Fraile, M. 2007. "La influencia del conocimiento político en las decisiones de voto." Revista Española de Investigaciones Sociológicas 120: 41-74.

Gaziano, C. 1997. "Forecast 2000: Widening Knowledge Gaps." Journalism and Mass Communication Quarterly 74 (2): 237-264.

Genova, B. K. L., and B. S. Greenberg. 1979. "Interest in News and Knowledge Gap." The Public Opinion Quarterly 43 (1): 79-91.

Gibson, R. K., Lusoli, W., and S. Ward. 2005. "Online Participation in the UK: Testing a 'Contextualised' Model of Internet Effects." British Journal of Politics and International Relations 7 (2): 561-583.

Graber, D. A. 1990. "Seeing is Remembering: How Visuals Contribute to Learning from Television News." Journal of Communication 40 (3): 134-155.

Graber, D. A. 1994. "Why Voters Fail Information Tests: Can the Hurdles be Overcome?." Political Communication 11 (4): 331-346.

Graber, D. A. 2004. "Mediated Politics and Citizenship in the Twenty-First Century". Annual Review of Psychology 55: 545-571.

Grönlund, K. 2007. "Knowing and Not Knowing. The Internet and Political Information." Scandinavian Political Studies 30 (3): 397-418.

Jerit, J., Barabas, J., and T. Bolsen. 2006. "Citizens, Knowledge, and the Information Environment." American Journal of Political Science 50 (2):266-282.

Johnson, T. J., Braima, M. A. M., and J. Sothirajah. 1999. "Doing the traditional media sidestep: Comparing the effects of the Internet and other non-traditional media with traditional media in the 1996 presidential campaign." Journalism and Mass Communication Quarterly 76 (1): 99-123.

Kenski, K., and N. J. Stroud. 2006. "Connections Between Internet Use and Political Efficacy, Knowledge,and Participation." Journal of Broadcasting and Electronic Media 50 (2):173 - 192.

Kim, S. H. 2008. "Testing the Knowledge Gap Hypothesis in South Korea: Traditional News Media, the Internet, and Political Learning." International Journal of Public Opinion Research 2 (2): 193-210.

Kim, S. H., Scheufele, D. A., and J. Shanahan. 2005. "Who Cares about Issues? Issue Voting and the Role of News Media during the 2000 US Presidential Election." Journal of Communication 55: 103-121.

Kim, Y. M. 2009. "Issue Publics in the New Information Environment. Selectivity, Domain Specificity, and Extremity." Communication Research 36 (2): 254-284.

Kwak, N. 1999. "Revisiting the Knowledge Gap Hypothesis: Education, Motivation, and Media Use." Communication Research 6 (4): 385-413.

Lassen, D. 2005. "The Effect of Information on Voter Turnout: Evidence from a Natural Experiment." American Journal of Political Science 49 (1):103-118.

Luskin, R. C. 1987. "Measuring Political Sophistication." American Journal of Political Science 31: 856899. 
Neuman, W. E., Just, M. R., and A. N. Crigler. 1992. Common Knowledge: News and the Construction of Political Meaning. Chicago: Chicago University Press.

Newton, K. 1999. "Mass Media Effects: Mobilization or Media Malaise?" British Journal of Political Science 29 (4): 577-599.

Norris, P. 2001. Digital Divide: Civic Engagement, Information Poverty, and the Internet worldwide. Cambridge: Cambridge University Press.

Norris, P. and M. Sanders. 2003. "Message or medium? Campaign learning during the 2001 British General Election", Political Communication 20: 233-262.

Noveck, B. S. 2000. "Paradoxical Partners: Electronic Communication and Electronic Democracy". Pp. 18-35 in The Internet, Democracy, and Democratization, edited by P. Ferdinand. London: Frank Cass.

Palfrey, T. R. and K. T. Poole. 1987. "The Relationship between Information, Ideology, and Voting Behavior." American Journal of Political Science 31 (3): 511-530.

Polat, R. K. 2005. "The Internet and Political Participation: Exploring the Explanatory Links." European Journal of Communication 20 (4): 435-459.

Prior, M. 2005. "News vs. Entertainment: How Increasing Media Choice Widens Gaps in Political Knowledge and Turnout." American Journal of Political Science 49 (3): 577-592.

Prior, M. 2007. Post-Broadcast Democracy: How Media Choice Increases Inequality in Political Involvement and Polarizes Elections. New York: Cambridge University Press.

Prior, M. 2009. Improving Media Effects Research through Better Measurement of News Exposure. Journal of Politics 71 (3): 893-908.

Schuefele, D. A. and M. Nisbet. 2002. "Being a Citizen Online: New Opportunities and Dead Ends". The Harvard Journal of Press/Politics 7 (3): 55-75.

Shah, D. V., Kwak, N. and R. L. Holbert. 2001. "'Connecting' and 'Disconnecting' With Civic Life: Patterns of Internet Use and the Production of Social Capital". Political Communication 18:141-162.

Sunstein, C. R. 2003. República.com. Internet, democracia y libertad. Barcelona: Paidós.

Sunstein, C. R. 2006. Infotopia.com. How Many Minds Produce Knowledge. Oxford: Oxford University Press.

Tichenor, P. J., Donohue, G. A. and C. N. Olien. 1970. "Mass Media Flow and Differential Growth in Knowledge". Public Opinion Quarterly 34: 159-170.

Van Dijk, J. 2006. "Digital Divide Research, Achievements and Shortcomings." Poetics 34 (4-5): 221-235.

Verba, S., Schlozman, K. L. and H. E. Brady. 1995. Voice and Equality: Civic Voluntarism in American Politics. Cambridge, Mass.: Harvard University Press.

Vettehen, P. G. H. H., Hagemann, C. P. M. and L. B. Van Snippenburt. 2004. "Political Knowledge and Media Use in the Netherdlands." European Sociological Review 20 (5): 415-424.

Zaller, J. 1992. The Nature and Origins of Mass Opinion. Cambridge: Cambridge University Press. 
EVA ANDUIZA is Associate professor of Political Science at the Universitat Autònoma de Barcelona. She holds a PhD from the European University Institute in Florence.Her main research lines deal with political behavior, political participation, and elections. She is the principal investigator of the research group "Democracy, Elections and Citizenship".

AINA GALLEGO is a postdoctoral visiting scholar at the Political Science Department of Stanford University. She holds a PhD in Political Science from the Universitat Autònoma de Barcelona. Her main research interests are inequality in political participation, the impact of personality and new technologies on political behavior, and comparative electoral systems.

LAIA JORBA HOLDS a PhD in Political Science from the Universitat Autònoma de Barcelona, where she has taught history of political ideas, and political theory. Her main fields of research are democratic innovation and democratic quality, political participation and digital media, and the socio-political integration of immigrants.

RECEIVED: 18 January 2010

ACCEPTED: 01 February 2011 


\section{APPENDIX 1. VARIABLES CODING}

Political knOWLedge: $0=$ No correct items; $0.33=1$ correct item; $0.67=2$ correct items; $1=3$ correct items INTEREST IN POLITICS: $0=$ =Not interested; $0.33=$ Not very interested; $0.67=$ Fairly interested; $1=$ Very interested PolitiCaL DISCUSSION: $0=$ Never; $0.17=$ Less than once a month; $0.33=$ Once a month; $0.5=$ Several times a month; $0.67=$ Once a week; $0.84=$ Several times a week; $1=$ Everyday

Education: $0=$ no schooling; 0.25= Primary education; 0.5=Lower secondary education; $0.75=$ Upper secondary education; $1=$ Tertiary education

TOTAL HOUSEHOLD INCOME (MONTHLY): $0=$ LesS than $€ 300 ; 0.11=€ 301$ to $€ 600 ; 0.22=€ 601$ to $€ 900$; $0.33=€ 901$ to $€ 1200 ; 0.44=€ 1201$ to $€ 1800 ; 0.55=€ 1801$ to $€ 2400 ; 0.66=€ 2401$ to $€ 3000 ; 0.88=€ 3001$ to $€ 4500 ; 0.88=€ 4501$ to $€ 6000 ; 1=$ More than $€ 6000$

AgE: Continuous in years. Minimum 18, maximum 95

Age SQUARED: Age squared

Woman: $0=$ Man; $1=$ Woman

FREQUENCY OF INTERNET USE: $0=$ No Internet use; $0.2=$ Less than a few times a month; $0.4=A$ few times a month; $0.6=1-2$ days per week; $0.8=3-5$ days per week; $1=6-7$ days a week

TELEVISION OR RADIO EXPOSURE (CONSUMPTION OF ANY CONTENT): $0=$ Never; $0.25=$ Less than one hour a day; $0.5=1-2$ hours a day; $0.75=2-3$ hours a day; $1=$ More than 3 hours a day

VIEWING OR LISTENING TO NEWS ON TV OR RADIO: $0=$ Never; $0.25=$ Less than once a week; $0.5=1-2$ days a week; $0.75=3-4$ days a week; $1=$ Everyday

SEARCH FOR POLITICAL INFORMATION ON THE INTERNET: 0=Never; $0.25=$ Less frequently; 0.5=Once a month; $0.75=$ Once a week; $1=$ More than once a week

SURFING THE NEWS WITH NO DEFINED AIM: $0=$ Does not use the Internet to surf with no purpose; $1=$ Uses the Internet to surf with no purpose

RECEPTION OF POLITICAL EMAILS: $0=$ has not received any political emails in the last 12 months; $1=$ has received a political email (with a criticism of or support for a party, a petition, information on a campaign or other political content) in the last 12 months 